\title{
Retinometer predicts visual outcome in Descemet membrane endothelial keratoplasty
}

\author{
Caroline Sophie Wald ${ }^{1} \cdot$ Jan Darius Unterlauft ${ }^{2} \cdot$ Matus Rehak $^{3} \cdot$ Christian Girbardt $^{1}{ }^{10}$
}

Received: 8 November 2021 / Revised: 15 February 2022 / Accepted: 21 February 2022 / Published online: 26 February 2022

(c) The Author(s) 2022

\begin{abstract}
Purpose To analyze the preoperative predictive value of retinometer visual acuity (VA) in eyes following Descemet membrane endothelial keratoplasty (DMEK).

Methods Patients undergoing DMEK between August 2011 and July 2020 were included. Preoperative interference visual acuity was assessed using Heine Lambda 100 Retinometer. Depending on the presence or absence of concomitant ocular disease, the Retinometer was evaluated for its ability to preoperatively predict best-corrected visual acuity (BCVA) six months after surgery using correlation, simple and multiple linear regression, contingency analyses, and receiver operating characteristic (ROC) analysis. Preoperative corneal backscatter was correlated with Retinometer prediction accuracy.

Results A total of 198 eyes were included in the analysis. There was a significant correlation between Retinometer VA and postoperative BCVA $(r=0.647, P<0.001)$. Regardless of the presence or absence of concomitant ocular disease and the surgery procedure (DMEK \& triple DMEK), Retinometer VA was the most significant predictor of postoperative BCVA $(P<0.001)$. ROC analysis revealed reliable diagnostic performance of the Retinometer (AUC $=0.829, P<0.001)$. A Retinometer VA $\geq 0.5$ accurately predicted a postoperative BCVA $\geq 0.5$ in $91 \%$ of cases. No association was found between corneal backscatter and prediction accuracy $(P=0.566)$.

Conclusions Retinometer VA can be used for preoperative prediction of postoperative BCVA in DMEK and triple DMEK patients, independent of increased backscatter values and the presence or absence of concomitant ocular disease. By using this simple but effective tool, indication for DMEK can be facilitated and postoperative outcomes can be realistically predicted preoperatively.
\end{abstract}

Keywords Retinometer $\cdot$ DMEK $\cdot$ Corneal transplantation $\cdot$ Interference visual acuity

\section{Key messages}

- Determining the ideal time for Descemet membrane endothelial keratoplasty (DMEK) and predicting potential postoperative visual outcome is a complex challenge.

- Interference visual acuity measurement via Retinometer can provide an accurate preoperative prediction of the visual outcome after DMEK independent of the presence or absence of concomitant ocular disease.

- Therefore, the Retinometer is a valuable tool for facilitating the indication for DMEK and for setting realistic preoperative outcome goals.

Christian Girbardt

christian.girbardt@medizin.uni-leipzig.de

1 Department of Ophthalmology, University of Leipzig Medical Center, Liebigstrasse 10-14, 04103 Leipzig, Germany

2 University Department of Ophthalmology, Inselspital, University of Bern, Bern, Switzerland

3 Department of Ophthalmology, University Hospital of Gießen and Marburg, Gießen, Germany

\section{Introduction}

Since its introduction in 2006 [1], Descemet membrane endothelial keratoplasty (DMEK) has been established as a safe and effective treatment for patients suffering from corneal endothelial disease [2]. Benefits of DMEK include nearly full restoration of corneal anatomy, fast visual rehabilitation time, excellent visual outcome, and low 
complication rates [1-5]. Consequently, DMEK has gained worldwide popularity in recent years and is increasing at the highest rate of performed procedures compared to any other keratoplasty technique in the USA and in Germany [6, 7]. DMEK procedures are expected to reach the numbers of PK and DSAEK procedures in the next few years [7]. In Germany, DMEK is already the most frequently performed keratoplasty procedure [6].

When surgeons decide to perform DMEK, they and their patients are highly interested in the expected postoperative visual outcome, especially in the presence of concomitant ocular disease. Preoperative measurement of BCVA determines visual acuity status, which is influenced by concomitant ocular disease such as media opacities.

For this purpose, preoperative measurement of interference visual acuity (VA) can be used. The optical principle of interference VA is the projection of two coherent light beams into the eye, creating a striped pattern on the retina. This allows assessment of retinal resolving power in isolation $[8,9]$, largely independent of refractive errors and moderate opacities of refractive media $[10,11]$. As a result, interference VA provides a preoperative estimation of expected postoperative VA. In clinical practice, a compact examination instrument called Retinometer can be used for the assessment of interference VA. This may help facilitate the indication for DMEK and avoid unnecessary surgery.

Previous studies have investigated the prognostic relevance of interference VA in cataract patients without [12-15] and with concomitant ocular disease [16-22] and in patients suffering from epiretinal gliosis [23-25]. Analyses in patients undergoing penetrating keratoplasty were performed using laser interferometer [26-28] and potential acuity meter $[28,29]$. So far, no interference VA measurements in DMEK patients have been published.

The extent of corneal decompensation as detected by corneal density measurements may interact with interference VA, as increased corneal backscatter values have been found in patients with Fuchs endothelial dystrophy (FED) at all stages of disease [30].

The purpose of this study was to evaluate the accuracy of interference VA in patients undergoing DMEK and to identify cutoff values that preoperatively predict DMEK outcome. Furthermore, the effect of corneal decompensation and presence of concomitant ocular disease on the accuracy of interference VA measurement were investigated.

\section{Material and methods}

\section{Study design}

Retrospective interventional case series.

\section{Study participants}

Data from patients receiving DMEK at the Department of Ophthalmology, University of Leipzig Medical Center, Germany, between August 2011 and July 2020 was reviewed. Retrospective data was collected until December 2018, with Retinometer VA documented in 212 cases. Since January 2019, the study was continued prospectively by systematically measuring interference VA in all DMEK patients $(n=69)$.

DMEK was performed by two experienced surgeons (CG, JDU) according to the technique published by Melles [1] and modified by Cursiefen [31]. In patients with concomitant cataract, phacoemulsification and posterior chamber lens implantation (triple DMEK) were performed within the same session.

\section{Retinal visual acuity}

Interference VA measurements were performed using Heine ${ }^{\circledR}$ Retinometer (Lambda $100 ®$ Retinometer, Heine Optotechnik GmbH \& Co. KG, Gilching, Germany), a hand-held device based on the principle of light interference. The device shows a spot of light projecting a circular interference pattern of alternating black and red stripes onto the patient's retina $[10,11,19]$. Both fineness and stripe pattern direction (horizontal, diagonal, vertical) can be varied to determine the finest stripe width at which pattern orientation is still correctly recognized by the patient. The Retinometer provides a range of seven distinct values within a VA range of 0.07 to 0.80 . Starting with the broadest pattern, a random stripe orientation was chosen. If recognized correctly by the patient, a finer stripe pattern and a new orientation were set. The value of the finest recognizable stripe pattern was recorded as Retinometer VA. According to the manufacturer's recommendations, measurements were performed in reduced ambient lighting and with dilated pupils. Although a measurement with optical correction is not necessary due to the independence of refractive errors $[10,11]$, we performed the measurements with best-spectacle correction to guarantee generalizability of the results.

\section{Data collection}

Preoperative central corneal thickness (CCT) and corneal backscatter in grey scale units (GSU) of the central annular zone at $0-2 \mathrm{~mm}$ from anterior corneal layer [32] were measured using Scheimpflug-based Oculus ${ }^{\circledR}$ Pentacam $®$ (Oculus GmbH, Wetzlar, Germany). Concomitant ocular disease and postoperative BCVA six months after DMEK were assessed. 
Exclusion criteria were intraoperative and postoperative complications that, in the surgeon's judgment, affected postoperative VA. Furthermore, subjects with inadequate cooperation or comprehension problems during Retinometer measurement leading to unreliable interpretation of data were excluded.

\section{Classification of ocular comorbidities}

Concomitant ocular disease was classified into five categories: (1) anterior segment pathology relevant to VA, (2) central fundus and vitreous body pathology relevant to VA, (3) glaucoma and other optic nerve defects, (4) amblyopia and non-organic visual loss, and (5) ocular conditions not relevant to VA. Patients with nonorganic vision loss were defined as deterioration of vision despite normal ophthalmologic examination including electrophysiologic testing. Patients were classified accordingly, with patients without concomitant ocular disease assigned to category 5. Multiple assignments within the first four categories per patient were possible. Allocations of each ocular pathology to the five categories are presented in Online Resource Table 1.

\section{Classification of estimation accuracy}

In order to analyze Retinometer prediction accuracy, eyes were categorized as in previous Retinometer studies [12]: underestimation (Retinometer VA $<\mathrm{BCVA}$ ), overestimation (Retinometer VA $>$ BCVA), and accurate estimation (Retinometer $\mathrm{VA} \triangleq \mathrm{BCVA}$ ).

As described by Rassow et al. [33], a postoperative BCVA range for which Retinometer prediction was considered correct was defined for each preoperative Retinometer VA value. Eyes with postoperative BCVA above one level of preoperative Retinometer VA were categorized as underestimation, whereas eyes with postoperative BCVA below one level of preoperative Retinometer VA were categorized as overestimation. If the BCVA was accurate or within \pm 1 lines of preoperative Retinometer measurement, this was interpreted as an accurate estimation.

\section{Statistical analysis}

Data was analyzed using SPSS $®$ (version 23 for Windows; SPSS Inc., Chicago, IL, USA). The scatterplot was created with R (version 4.1.0 for Windows; R Core Team, R Foundation For Statistical Computing, Vienna, Austria). If data from a patient's right and left eyes were eligible, one eye was randomly selected according to the recommendation of Armstrong et al. [34], in order to exclude statistical bias due to possible correlation between the left and right eye of a subject. Preoperative Retinometer VA and postoperative BCVA were transformed into logarithmically graded ranks as shown in Online Resource Table 2 (modified according to Schulze et al. [20]). Transformation into ranks was performed to include low VA (hand movement $=1$, finger counting $=2$ ) and to prevent bias in the statistical analysis due to the varying distances between the values.

Retinometer prediction accuracy was defined as BCVA minus Retinometer VA. The proportion of variance explained (PVE) in postoperative BCVA rank by Retinometer VA rank and concomitant ocular disease categories was computed following Shim et al. [35].

We performed descriptive analysis and Fisher's exact test for analysis of categorical variables. Correlations were performed using Pearson coefficient $r$. Analogous to the interpretation in Schaub et al. [36] correlation was interpreted as strong $(r \pm 0.70)$, moderate $(r \pm 0.50)$, or weak $(r \pm 0.30)$, depending on which value $r$ was closest to. Simple and multiple linear regressions were performed to assess the predictive value of the independent variables Retinometer VA and individual concomitant ocular disease. Diagnostic performance was evaluated by using receiver operating characteristic (ROC) analysis to calculate the area under the curve (AUC). The higher the AUC, the more accurate the test. Sensitivity, specificity, positive (PPV), and negative predictive value (NPV) were calculated. Sensitivity indicates the percentage of patients with $\mathrm{BCVA} \geq 0.5$ for whom the Retinometer indicated VA $\geq 0.5$. Specificity indicates the percentage of patients with BCVA $<0.5$ for whom the Retinometer indicated VA $<0.5$. The PPV represents the patient percentage with a Retinometer $\mathrm{VA} \geq 0.5$ that had a $B C V A \geq 0.5$. The NPV states the percentage of patients with a Retinometer VA $<0.5$ who had a BCVA $<0.5$.

The level of significance was defined as $P<0.05$.

\section{Results}

A total of 281 eyes were examined. Afterwards, one eye was randomly selected in subjects for whom data were available from both eyes. There was a moderate negative correlation $(n=206, r=-0.554, P<0.001)$ between corneal thickness and Retinometer VA rank. Outliers within the normal distribution of corneal thickness were identified in corneas more than twice as thick than the average of $550 \mu \mathrm{m}$. To avoid statistical bias, only eyes with corneal thickness values $\leq 1100 \mu \mathrm{m}(n=198)$ were included for further analysis.

Descriptive analysis and clinical outcomes of the study cohort are presented in Table 1.

There was a moderate positive correlation between Retinometer VA rank and BCVA rank $(n=198, r=0.647$, $P<0.001)$. Retinometer VA rank correlated significantly with BCVA rank both in DMEK alone and triple DMEK (DMEK, $n=119, r=0.668, P<0.001$; triple DMEK, $n=79$, $r=0.321, P<0.001)$. Comparison of postoperative BCVA 
Table 1 Clinical baseline data of the study cohort $(n=198)$

Age (years)

Preoperative retinometer VA

Postoperative BCVA

Preoperative corneal thickness $(\mu \mathrm{m})$

Preoperative corneal backscatter (GSU, $n=39$ )

Gender

Surgery

Indication

Presence of ocular comorbidities

$\begin{array}{lll} & \text { Mean } \pm \text { SD } \\ & 72.4 \pm 7.8 & \\ & 0.5 \pm 0.2 & \\ & 0.6 \pm 0.2 & \\ & 661.3 \pm 89.8 & \\ & 47.6 \pm 19.9 & (\%) \\ \text { Female } & \mathrm{n} & (68) \\ \text { Male } & 134 & (32) \\ \text { Pseudophakic DMEK } & 64 & (60.1) \\ \text { Triple DMEK } & 119 & (39.9) \\ \text { Fuchs endothelial dystrophy } & 79 & (89.9) \\ \text { Pseudophakic bullous keratopathy } & 178 \\ \text { Re-DMEK } & 14 & (7.1) \\ \text { Anterior segment pathology relevant to VA } & 6 & (3.0) \\ \text { Central fundus and vitreous body pathology relevant } & 56 & (20.7) \\ \text { to VA } & 109 & (28.3) \\ \text { Glaucoma and other optic nerve defects } & 41 & \\ \text { Amblyopia and non-organic VA loss } & 36 & (18.2) \\ & 8 & (4) \\ & & \end{array}$

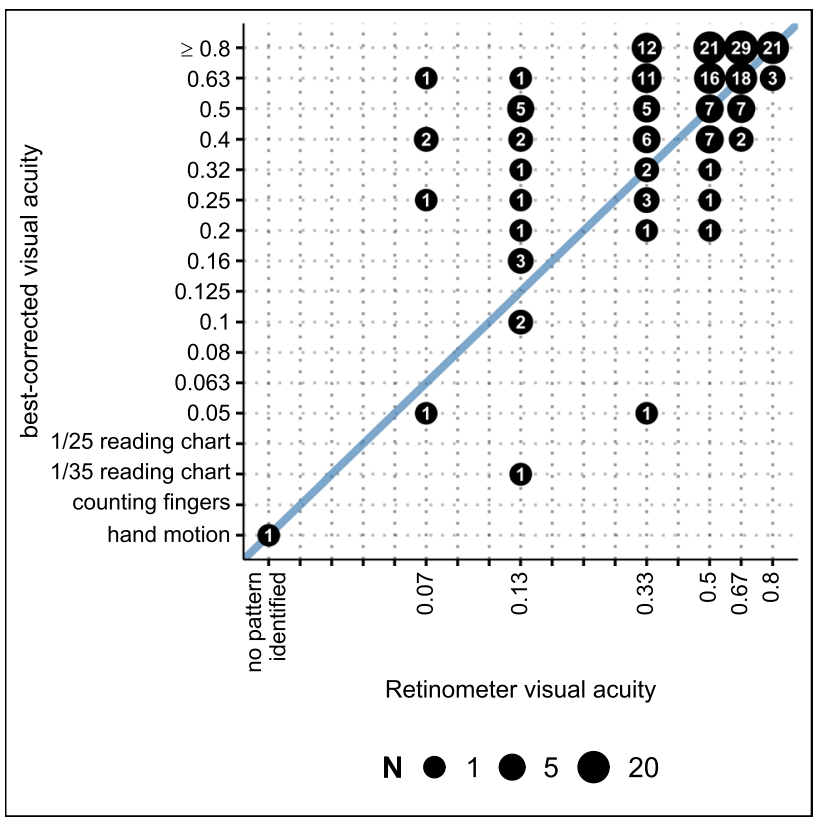

Fig. 1 Correlation between preoperative Retinometer VA ranks and BCVA ranks (Pearson's correlation coefficient $r=0.647, P<0.001$ )

rank and preoperative Retinometer VA rank is displayed in Fig. 1.

Within each category of existing concomitant ocular disease, there was a strong correlation between Retinometer VA rank and BCVA rank: (1) anterior segment pathology relevant to VA $(n=41, r=0.788, P<0.001)$ and (4) amblyopia and non-organic visual loss $(n=8, r=0.769, P=0.05)$. Within the category (2) central fundus and vitreous body pathology relevant to VA $(n=56, r=0.507, P<0.001)$ and (3) glaucoma \& other optic nerve defects $(n=36, r=0.656$, $P<0.001)$, there was a moderate correlation.

Overall, the Retinometer demonstrated accurate estimation accuracy and was not affected by the presence of different concomitant ocular pathologies (Table 2).

There was no significant correlation between prediction accuracy and corneal backscatter $(n=39, r=-0.095$, $P=0.566)$.

Simple linear regression models showed that Retinometer VA rank was a significant predictor of BCVA rank, independent of the presence $(n=109, \mathrm{~B}$ coefficient $=0.596, \beta$ coefficient $=0.617, P<0.001,95 \%$ confidence interval $[\mathrm{CI}]$ 0.45 to 0.74 , adjusted $R^{2}=0.375$ ) or absence of concomitant ocular disease $(n=89$, B coefficient $=0.296, \beta$ coefficient $=0.505, P<0.001,95 \%$ CI 0.18 to 0.40 , adjusted $\left.R^{2}=0.247\right)$.

A multiple linear regression analysis incorporating Retinometer VA rank and the four categories of existing concomitant ocular disease as potential interacting predictors of postoperative BCVA rank $(n=198, P<0.001$, adjusted $\left.R^{2}=0.529\right)$ showed all variables as significant predictors of postoperative BCVA rank. Among all variables, the proportion of variance in the rank of BCVA was most significantly explained by the rank of Retinometer VA $(n=198$, B coefficient $=0.464, \beta$-coefficient $=0.507, P<0.001,95 \%$ CI 0.37 to $0.56, \mathrm{PVE}=0.313$ ). 
Table 2 Retinometer prediction accuracy depending on concomitant ocular disease

\begin{tabular}{|c|c|c|c|c|c|c|c|}
\hline & \multicolumn{2}{|c|}{ Underestimation } & \multicolumn{2}{|c|}{$\begin{array}{l}\text { Accurate esti- } \\
\text { mation }\end{array}$} & \multicolumn{2}{|c|}{ Overestimation } & \multirow{2}{*}{$\begin{array}{l}\text { Tota } \\
n\end{array}$} \\
\hline & $n$ & $(\%)$ & $n$ & $(\%)$ & $n$ & $(\%)$ & \\
\hline Anterior segment pathology relevant to VA & 12 & $29.3 \%$ & 29 & $70.7 \%$ & 0 & $0.0 \%$ & 53 \\
\hline $\begin{array}{l}\text { Central fundus and vitreous body pathology } \\
\text { relevant to VA }\end{array}$ & 15 & $26.8 \%$ & 39 & $69.6 \%$ & 2 & $3.6 \%$ & 73 \\
\hline Glaucoma and other optic nerve defects & 10 & $27.8 \%$ & 26 & $72.2 \%$ & 0 & $0.0 \%$ & 47 \\
\hline Amblyopia and non-organic & 1 & $12.5 \%$ & 6 & $75 \%$ & 1 & $12.5 \%$ & 14 \\
\hline
\end{tabular}

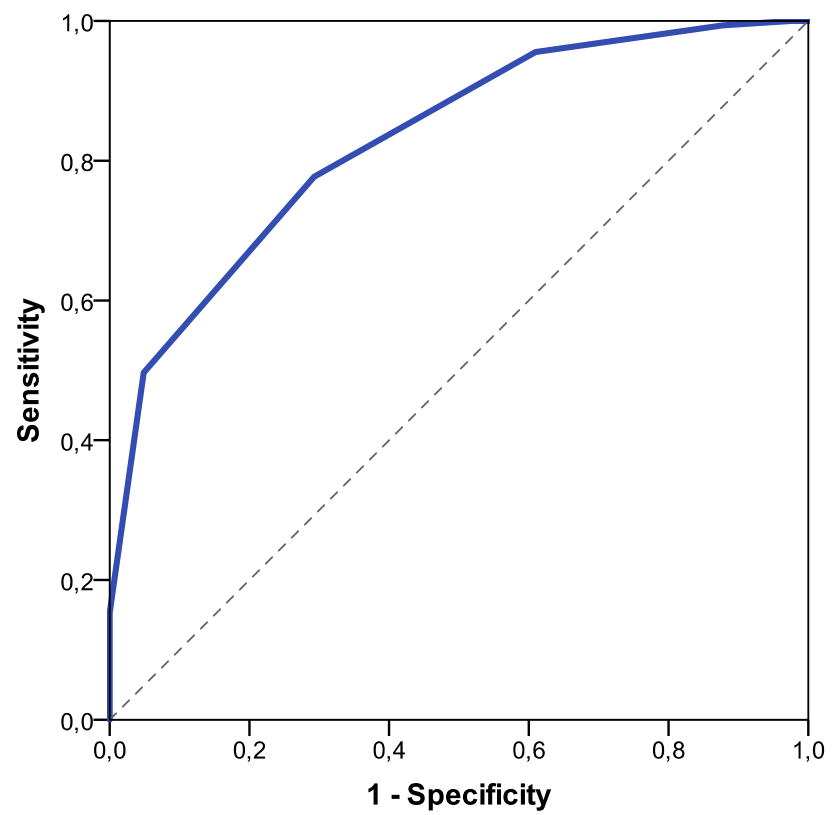

Fig. 2 Receiver operating characteristic analysis assessing the sensitivity and specificity of the Retinometer for discriminating between postoperative $\mathrm{BCVA} \geq 0.5$ and $<0.5$

The ROC curve assessing diagnostic performance for discriminating between postoperative $\mathrm{BCVA} \geq 0.5$ and $<0.5$, respectively, had an AUC of 0.829 (95\% CI 0.76 to $0.90 P<0.001)$ and is displayed in Fig. 2. Based on this analysis, a Retinometer VA rank cutoff $\geq 14$, corresponding approximately to a Retinometer VA $\geq 0.5$, had a sensitivity of $77.7 \%$ and a specificity of $70.7 \%$ for predicting postoperative $\mathrm{BCVA} \geq 0.5$.

The significant association between Retinometer VA $\geq 0.5$ and BCVA $\geq 0.5$ was confirmed using Fisher's exact test $(n=198, P<0.001)$, with a sensitivity of $77.7 \%$ and a specificity of $70.7 \%$. If the Retinometer predicted VA $\geq 0.5$, BCVA was $\geq 0.5$ in $91 \%$ of cases (PPV). However, in $45.3 \%$ of patients with a Retinometer $\mathrm{VA}<0.5$, the postoperative BCVA was $<0.5$ (NPV). In only $8.96 \%$ of cases, postoperative BCVA was $<0.5$ despite a Retinometer prediction of $\mathrm{VA} \geq 0.5$.
There was a significant association between Retinometer $\mathrm{VA} \geq 0.5$ and postoperative $\mathrm{BCVA} \geq 0.5$ within the comorbidity categories anterior segment pathology relevant to VA $(P=0.017)$, VA relevant changes of the central fundus and vitreous body $(P<0.001)$, and glaucoma and other optic nerve defects $(P<0.001)$, but not within the category amblyopia and non-organic VA loss $(P=1.00)$.

\section{Discussion}

This study is the first to systematically analyze the prognostic relevance of preoperative interference VA measurements in patients undergoing DMEK. For both the surgeon and the patient, a preoperative parameter should be determined that can facilitate decision-making for performing DMEK and provide prognostically significant information. In FED patients, several parameters have already been identified to facilitate decision-making and assist in predicting postoperative outcome after DMEK: preoperative BCVA [37], corneal backscatter $[30,32,36]$ and other densitometry parameters, preoperative corneal thickness $[32,38]$, the course of visual restitution of the first eye [38], and the graft's baseline endothelial cell density [38]. Nevertheless, none of the parameters examined in studies so far could provide an accurate preoperative prediction of the visual outcome after DMEK.

Patients with concomitant ocular diseases were mostly excluded in previous studies. To better transfer the results to clinical practice, patients with concomitant ocular disease were included in this study.

The Retinometer can be used to predict the expected postoperative BCVA by measuring the resolving power of the retina in isolation $[8,9]$, largely independent of refractive errors and of moderate opacities of the refractive media [10, $11]$.

In patients receiving penetrating keratoplasty, interference VA has been identified as a valuable tool for clinical decision-making for preoperative assessment of postoperative $\mathrm{BCVA}$, even in presence of additional concomitant ocular disease [26-28]. In general, good preoperative interferometric VA was identified as being predictive for 
good postoperative VA, whereas poor interferometric VA in patients having opacified media did not predict good postoperative VA [27]. In these studies, the Pearson correlation coefficient was not determined. According to Enoch et al. [27], the Retinometer underestimated or accurately estimated postoperative BCVA in $55.6 \%$ of cases, compared to $70 \%$ of cases as reported by Gstalder et al. [26] and 69.9\% as reported by Steinert et al. [28].

The Retinometer showed a moderate tendency to underestimate VA in previous cataract studies $[10,12]$ and a tendency to overestimate VA in the presence of amblyopia [10, 23, 26, 33] or maculopathy [23].

In this study, the Retinometer revealed an accurate estimation tendency in the majority of cases. Nevertheless, the rate of underestimation was higher than the rate of overestimation. Furthermore, Retinometer VA was shown to be a significant predictor of BCVA after DMEK, regardless of the presence or absence of concomitant ocular disease. Because backscatter did not affect prediction accuracy, the Retinometer can be used reliably in patients with corneal decompensation, as occurs during the course of corneal endothelial diseases [30]. There was a significant correlation between Retinometer VA rank and BCVA rank in both DMEK alone and triple DMEK, demonstrating the Retinometer's ability for preoperative VA prediction in both contexts.

Additionally, the Retinometer was capable of significantly discriminating between postoperative $\mathrm{BCVA} \geq$ and $<0.5$ within each category of existing ocular comorbidity, except for patients suffering from amblyopia and non-organic VA loss. Furthermore, it had a very high PPV (91\%). If Retinometer VA is good, the indication for DMEK can be given without hesitation and with prospect of positive outcome. In only $45.3 \%$ of patients with Retinometer VA $<0.5$, postoperative BCVA was $<0.5$ (NPV). This indicates that if Retinometer VA is poor, the patient may still benefit from surgery. Accordingly, surgery should not be rejected purely based on poor Retinometer VA. This observation supports the assumption that the Retinometer may tend to moderately underestimate postoperative VA, meaning that in clinical practice, postoperative BCVA is mostly as good as or even better than the predicted Retinometer VA.

Because predicted VA was higher than the actual postoperative BCVA in only $8.96 \%$ of the cases, there is little concern about a potentially disappointing overestimation of postoperative VA through the Retinometer.

A limitation of this study is that Retinometer measurements were performed in the retrospective cases only if the indication for DMEK was controversial. Prospective data of all subsequent DMEK patients collected was able to mitigate this selection bias. There might be several reasons why the correlation coefficient of 0.647 has only moderate strength. Both measurement methods are subjective and rely on the correct collaboration with the patient. There was no averaging of the values by repeated measurements. Furthermore, Retinometer is not capable of measuring precisely the same metric values as in BCVA measurement, but only certain levels. Categorization was used to reduce this bias.

In addition, the numbers of cases within each comorbidity category, especially in amblyopia and non-organic visual loss, and the number of corneal backscatter values were relatively low. Due to this fact, a prospective study with higher case numbers would be desirable. Another limitation is the potentially low generalizability of the study results due to the study cohort predominantly consisting of patients with Fuchs endothelial dystrophy.

In conclusion, this study demonstrates the prognostic relevance of preoperative Retinometer VA for postoperative BCVA six months after DMEK. The Retinometer can be used even in the presence of concomitant ocular disease. Therefore, the Retinometer is a valuable tool for facilitating the indication for DMEK, for avoiding unnecessary surgery, and for setting realistic preoperative outcome goals.

Supplementary Information The online version contains supplementary material available at https://doi.org/10.1007/s00417-022-05605-w.

Acknowledgements We would like to thank Dr. Holger Kirsten for his support in the statistical analysis (Institute for Medical Informatics, Statistics and Epidemiology IMISE of the University Leipzig Medical Faculty, Germany).

Funding Open Access funding enabled and organized by Projekt DEAL.

\section{Declarations}

Ethics approval This study followed the tenets of the Declaration of Helsinki and was approved by the responsible ethics committee at the University of Leipzig Medical Center.

Consent for publication All named authors meet the International Committee of Medical Journal Editors (ICMJE) criteria for authorship for this article, take responsibility for the integrity of the work as a whole, and have given their approval for this version to be published.

Conflict of interest The authors declare no competing interests.

Open Access This article is licensed under a Creative Commons Attribution 4.0 International License, which permits use, sharing, adaptation, distribution and reproduction in any medium or format, as long as you give appropriate credit to the original author(s) and the source, provide a link to the Creative Commons licence, and indicate if changes were made. The images or other third party material in this article are included in the article's Creative Commons licence, unless indicated otherwise in a credit line to the material. If material is not included in the article's Creative Commons licence and your intended use is not permitted by statutory regulation or exceeds the permitted use, you will need to obtain permission directly from the copyright holder. To view a copy of this licence, visit http://creativecommons.org/licenses/by/4.0/. 


\section{References}

1. Melles GRJ, Ong TS, Ververs B et al (2006) Descemet membrane endothelial keratoplasty (DMEK). Cornea 25(8):987-990. https:// doi.org/10.1097/01.ico.0000248385.16896.34

2. Deng SX, Lee WB, Hammersmith KM et al (2018) Descemet membrane endothelial keratoplasty: safety and outcomes: a report by the American Academy of Ophthalmology. Ophthalmology 125(2):295-310. https://doi.org/10.1016/j.ophtha.2017.08.015

3. Price MO, Giebel AW, Fairchild KM et al (2009) Descemet's membrane endothelial keratoplasty: prospective multicenter study of visual and refractive outcomes and endothelial survival. Ophthalmology 116(12):2361-2368. https://doi.org/10.1016/j.ophtha. 2009.07.010

4. Ham L, Balachandran C, Verschoor CA et al (2009) Visual rehabilitation rate after isolated descemet membrane transplantation: descemet membrane endothelial keratoplasty. Arch Ophthalmol 127(3):252-255. https://doi.org/10.1001/archophthalmol.2008.619

5. Anshu A, Price MO, Price FW (2012) Risk of corneal transplant rejection significantly reduced with Descemet's membrane endothelial keratoplasty. Ophthalmology 119(3):536-540. https:// doi.org/10.1016/j.ophtha.2011.09.019

6. Flockerzi E, Maier P, Böhringer D et al (2018) Trends in corneal transplantation from 2001 to 2016 in Germany: a report of the DOG-section cornea and its keratoplasty registry. Am J Ophthalmol 188:91-98. https://doi.org/10.1016/j.ajo.2018.01.018

7. Eye Bank Association of America (2019) 2019 Eye banking statistical report. https://restoresight.org/wp-content/uploads/2020/ 04/2019-EBAA-Stat-Report-FINAL.pdf. Accessed 29 June 2021

8. Charman WN, Simonet P (1997) Yves Le Grand and the assessment of retinal acuity using interference fringes. Ophthalmic Physiol Opt 17(2):164-168

9. Campbell FW, Green DG (1965) Optical and retinal factors affecting visual resolution. J Physiol 181(3):576-593. https://doi.org/ 10.1113/jphysiol.1965.sp007784

10. Lachenmayr B (1990) Sehschärfevorhersage bei Medientrübungen und nicht korrigierbaren Refraktionsfehlern, Prüfung der sog. "retinalen Sehschärfe" [Predicting visual acuity in media opacities and uncorrectable refractive errors. Assessing so-called "retinal visual acuity"]. Fortschr Ophthalmol 87(Suppl):118-37

11. Rassow B, Wolf D (1977) Die Messung der "retinalen Sehschärfe" mit dem Laserinterferenzgerät als klinische Routinemethode [Testing of the "retinal acuity" with the laser interference apparatus as a routine clinical method]. Adv Ophthalmol 34:116-142

12. Mimouni M, Shapira Y, Jadon J et al (2017) Assessing visual function behind cataract: preoperative predictive value of the Heine Lambda 100 retinometer. Eur J Ophthalmol 27(5):559-564. https://doi.org/10.5301/ejo.5000993

13. Tharp A, Cantor L, Yung CW et al (1994) Prospective comparison of the Heine retinometer with the Mentor Guyton-Minkowski potential acuity meter for the assessment of potential visual acuity before cataract surgery. Ophthalmic Surg 25(9):576-579

14. Colombo-Barboza GN, Hida WT, van den Berg A et al (2010) Confiabilidade da previsão da acuidade visual pós-operatória de catarata mediante medição da acuidade visual pré-operatória utilizando o retinômetro Heine Lambda 100 [Reliability of predictable postoperative visual acuity of cataracts as measured by Heine Lambda 100 retinometer preoperatively]. Arq Bras Oftalmol 73(3):244-249. https://doi.org/10.1590/s0004-27492010000300007

15. Rassow B, Wolf D (1973) Erfahrungen mit dem Laser-Interferenzstreifen-Test bei der Messung des retinalen Auflösungsvermögens [Experiences with the laser-interference stripe test for the measurement of retinal resolution capacity]. Albrecht Von Graefes Arch Klin Exp Ophthalmol 187(1):61-66. https://doi.org/10.1007/ BF00444146
16. Makabe R (1980) Retinometeruntersuchungen bei Katarakt [Retinometer examinations in cataract patients (author's transl)]. Klin Monbl Augenheilkd 176(5):806-807. https://doi.org/10.1055/s2008-1057557

17. Richard G, Mewe L (1982) Zur prognostischen Bedeutung der Retinometeruntersuchung [The prognostic significance of retinometer studies]. Fortschr Ophthalmol 79(4):346-349

18. Menne K, Kohl M, Trinkmann R et al (1987) Der Wert der präoperativen Retinometeruntersuchung bei Katarakt-Patienten [Value of preoperative retinometer study in cataract patients]. Fortschr Ophthalmol 84(2):180-182

19. Mistlberger A, Alzner E (1995) Ein neues Retinometer (Heine Lambda 100) im Vergleich mit dem Interferometer (Interzeag IRAS 760) bei der präoperativen Evaluierung der KataraktPatienten [A new retinometer (Heine Lambda 100) in comparison with the interferometer (Interzeag IRAS 760) for the preoperative evaluation of patients with cataract]. Spektrum Augeheilkd 9(2):77-79. https://doi.org/10.1007/BF03163760

20. Schulze S, Köhler K, Schüller C (2005) Vorhersage des postoperativen Visus bei Cataracta matura und Cataracta myopica alta [Prediction of the postoperative visual acuity in mature cataract and high myopic cataract]. Spektrum Augeheilkd 19(5):270-272. https://doi.org/10.1007/BF03163458

21. Bamahfouz AY, Al-Ghamdi AA, Subhan IA, Hawsawi RA (2015) Prediction of post phacoemulsification visual acuity in patients with different degree of lens opacity using Heine retinometer. Int J Sci Stud 3(3):105-109. https://doi.org/10.17354/ijss/2015/280

22. Wolf D, Rassow B (1977) Zur Untersuchung der "Retinalen Sehschärfe" bei Patienten mit Medientrübungen [Study of "retinal visual acuity" in patients with media opacity]. Ber Zusammenkunft Dtsch Ophthalmol Ges 74:703-705

23. Kroll P, Normann J, Busse H (1985) Epiretinale Gliose ("Macular Pucker")-Indikation zur Vitrektomie in Abhängigkeit vom Retinometerwert [Epiretinal gliosis (macular pucker)-indications for vitrectomy in relation to the retinometer value]. Klin Monbl Augenheilkd 187(3):202-204. https://doi.org/10.1055/s-20081051017

24. Leisser C, Bartl G (2004) Vergleich des präoperativen Retinometerwertes mit dem postoperativen Visus nach Chirurgie epiretinaler Membranen [Comparison of preoperative retinometer values with postoperative visual acuity after surgery of epiretinal membranes]. Klin Monbl Augenheilkd 221(6):485-488. https://doi. org/10.1055/s-2004-813283

25. Leisser C, Bartl G (2005) Vergleich von Retinometer und Visus: eine Pilotstudie mit Patienten nach Chirurgie epiretinaler Membranen [Comparison of retinometer and visual acuity: a pilotstudy with patients after surgery of epiretinal membranes]. Spektrum Augeheilkd 19(3):168-170. https://doi.org/10.1007/BF031 63389

26. Gstalder RJ, Green DG (1972) Laser interferometry in corneal opacification. Preoperative visual potential estimation. Arch Ophthalmol 87(3):269-274. https://doi.org/10.1001/archopht.1972. 01000020271006

27. Enoch JM, Bedell HE, Kaufman HE (1979) Interferometric visual acuity testing in anterior segment disease. Arch Ophthalmol 97(10):1916-1919. https://doi.org/10.1001/archopht.1979.01020 020364017

28. Steinert RF, Minkowski JS, Boruchoff SA (1984) Pre-keratoplasty potential acuity evaluation. Laser interferometer and potential acuity meter. Ophthalmology 91(10):1217-1221. https://doi.org/10. 1016/s0161-6420(84)34172-0

29. Smiddy WE, Horowitz TH, Stark WJ et al (1987) Potential acuity meter for predicting postoperative visual acuity in penetrating keratoplasty. A new method using a hard contact lens. Ophthalmology 94(1):12-16. https://doi.org/10.1016/s0161-6420(87) $33511-0$ 
30. Wacker K, McLaren JW, Amin SR et al (2015) Corneal highorder aberrations and backscatter in Fuchs' endothelial corneal dystrophy. Ophthalmology 122(8):1645-1652. https://doi.org/10. 1016/j.ophtha.2015.05.005

31. Cursiefen C, Kruse FE (2010) DMEK: posteriore lamelläre Keratoplastiktechnik [DMEK: Descemet membrane endothelial keratoplasty]. Ophthalmologe 107(4):370-376. https://doi.org/10.1007/ s00347-010-2155-2

32. Arnalich-Montiel F, Mingo-Botín D, de Arriba-Palomero P (2019) Preoperative risk assessment for progression to Descemet membrane endothelial keratoplasty following cataract surgery in Fuchs endothelial corneal dystrophy. Am J Ophthalmol 208:76-86. https://doi.org/10.1016/j.ajo.2019.07.012

33. Rassow B, Rätzke P (1977) Der prognostische Wert der Bestimmung der retinalen Sehschärfe bei Patienten mit Katarakt [The prognostic value of the laser-interference-fringe-test with cataract patients (author's transl)]. Klin Monbl Augenheilkd 171(4):643-650

34. Armstrong RA (2013) Statistical guidelines for the analysis of data obtained from one or both eyes. Ophthalmic Physiol Opt 33(1):7-14. https://doi.org/10.1111/opo.12009
35. Shim H, Chasman DI, Smith JD et al (2015) A multivariate genome-wide association analysis of $10 \mathrm{LDL}$ subfractions, and their response to statin treatment, in 1868 Caucasians. PLoS ONE 10(4):e0120758. https://doi.org/10.1371/journal.pone.0120758

36. Schaub F, Gerber F, Adler W et al (2019) Corneal densitometry as a predictive diagnostic tool for visual acuity results after Descemet membrane endothelial keratoplasty. Am J Ophthalmol 198:124129. https://doi.org/10.1016/j.ajo.2018.10.002

37. Schrittenlocher S, Bachmann B, Tiurbe AM et al (2019) Impact of preoperative visual acuity on Descemet membrane endothelial keratoplasty (DMEK) outcome. Graefes Arch Clin Exp Ophthalmol 257(2):321-329. https://doi.org/10.1007/s00417-018-4193-4

38. Brockmann T, Pilger D, Brockmann C et al (2019) Predictive factors for clinical outcomes after primary Descemet's membrane endothelial keratoplasty for Fuchs' endothelial dystrophy. Curr Eye Res 44(2):147-153. https://doi.org/10.1080/02713683.2018. 1538459

Publisher's note Springer Nature remains neutral with regard to jurisdictional claims in published maps and institutional affiliations. 